\title{
The implementation of a blood conservation strategy in critical care on transfusion requirements
}

\author{
A Tridente $^{1 *}$, E Smith $^{1}$, N Dempsey-Hibbert ${ }^{2}$, S Bonney ${ }^{1}$, P Nee ${ }^{1}$ \\ From ESICM LIVES 2015 \\ Berlin, Germany. 3-7 October 2015
}

\section{Introduction}

Patients admitted to intensive care units (ICUs) are commonly affected by anaemia, which is contributed to by iatrogenic blood loss from diagnostic testing [1], with potential risks of increasing transfusion requirements and negative effect on outcomes [2]. Recently published guidelines make several recommendations for the management of anaemia and red blood cells (RBCs) transfusion in adult ICU patients [3].

\section{Objectives}

We aimed at determining whether a 3 components blood conservation strategy (BCS) can reduce blood volume drawn and/or RBCs transfusion requirements.

\section{Methods}

The BCS consisted of 3 components:

1) Use of a HemoDraw blood conservation device at arterial or venous access to eliminate the need to discard blood prior to sampling

2) Use of paediatric sample tubes instead of adult ones for haematology tests, and half-filled adult sample containers for biochemistry tests

3) Raised awareness of the benefits of a restrictive transfusion policy on critical care.

The BCS was introduced in our ICU between 01/04/ 14 and 30/09/14 (period 2) for all adult level 3 critical care patients. A comparable retrospective control group of the same time period in 2013 was used (period 1).

Multiple linear regression analysis, adjusted for age, gender, APACHE II score and ICU length of stay (LOS), was used to assess the influence of the BCS on blood volume drawn. Logistic regression analysis was used to assess influence on likelihood of RBCs transfusion.

${ }^{1}$ Whiston Hospital, Liverpool, United Kingdom

Full list of author information is available at the end of the article
STATA 10.1 (http://www.stata.com) was used for all analyses.

\section{Results}

A total of 377 patients were recruited (198 for period 1, 179 for period 2), 208 (55.2\%) were male. Median (IQR, interquartile range) age was $60(45-73)$ years, median (IQR) APACHE II score was 17 (11-22), median (IQR) LOS was 3.7 (1.7-8.7) days. The median (IQR) blood volume drawn was $113.8(48-252.1) \mathrm{ml}$ for period 1 and 53.8 (18.8-111.2) $\mathrm{ml}$ for period 2. After correction for age, gender, APACHE II score, ICU LOS, the use of the BCS in period 2 was associated with a reduction of $88.5 \mathrm{ml}$ (95\% CI 71-105.9, $\mathrm{p}<0.001$ ) in blood drawn for diagnostic testing. There was no significant difference in likelihood of RBCs transfusion (OR 1.2, 95\% CI 0.73-1.95, $\mathrm{p}=0.49$ ).

\section{Conclusions}

Use of a BCS in critical care significantly reduced the volume of blood drawn for diagnostic testing during ICU stay, but a significant decrease in transfusion requirements could not be demonstrated.

\section{Authors' details}

${ }^{1}$ Whiston Hospital, Liverpool, United Kingdom. ${ }^{2}$ Manchester Metropolitan University, Manchester, United Kingdom.

Published: 1 October 2015

\section{References}

1. Tinmouth A, Mclntyre L, Fowler R: 'Blood conservation strategies to reduce the need for red blood cell transfusion in critically ill patients.'. Canadian Medical Association Journal 2008, 178(1):49-57.

2. Rudis M, Jacobi J, Hassan E, Dasta J: 'Managing anemia in the critically ill patient.'. Pharmacotherapy 2004, 24(2):229-247.

3. Retter A, Wyncoll D, Pearse R, et al: 'Guidelines on the management of anaemia and red cell transfusion in adult critically ill patients.'. British Journal of Haematology 2012, 160:445-464.

doi:10.1186/2197-425X-3-S1-A822

Cite this article as: Tridente et al: The implementation of a blood

conservation strategy in critical care on transfusion requirements. Intensive Care Medicine Experimental 2015 3(Suppl 1):A822.

\section{SpringerOpen ${ }^{\circ}$}

( 2015 Tridente et al.; This is an Open Access article distributed under the terms of the Creative Commons Attribution License (http:// creativecommons.org/licenses/by/4.0), which permits unrestricted use, distribution, and reproduction in any medium, provided the original work is properly cited. 